Selfless and strategic, interpersonal and institutional: A continuum of paradoxical organizational compassion dimensions ${ }^{1}$

\author{
Maria L Araújo* \\ E-mail: $\underline{\text { mmle@sapo.pt }}$
}

Ace V Simpson

E-mail: ace.simpson@uts.edu.au

UTS Business School, University of Technology Sydney

14-28 Ultimo Road, Ultimo NSW 2007

Tel: +61295143278

Helena Á Marujo*

E-mail: hmarujo@iscsp.ulisboa.pt

Miguel P Lopes*

E-mail: mplopes@iscsp.ulisboa.pt

* Instituto Superior de Ciências Sociais e Políticas, Universidade de Lisboa

* CAPP- Centro de Administração e Políticas Públicas, Universidade de Lisboa Rua Almerindo Lessa

1300-663 Lisboa, Portugal

Tel: +351- 213619430

Selfless and strategic, interpersonal and institutional: A continuum of organizational compassion dimensions

\footnotetext{
1 'This work was supported by Portuguese national funds through FCT - Fundação para a Ciência e a Tecnologia, under project «PEST-OE/CJP/UI0713/2013». The authors would like to thank Professor Carl Rhodes and Dr Marco Berti for their comments on earlier drafts of this manuscript.
} 


\begin{abstract}
We asked 32 professionals what organizational compassion is to them. Analysis of the responses revealed four conflicting, if not paradoxical, dimensions. With insight from Habermas' theory of 'communicative action', we paired these dimensions as two lifeworld/system couples: (1) selfless compassion (lifeworld) and strategic compassion (system), as well as (2) interpersonal compassion (lifeworld) and institutional compassion (system). While the colonisation of the lifeworld by system dimensions is a legitimate Habermasian concern, our analysis highlights the potential for system to magnify the power of compassion beyond lifeworld contexts, leveraging and transcending lifeworld/system tensions, aided by dialogue as ‘communicative action'.
\end{abstract}

\title{
Keywords
}

Compassion, organization, organizational behaviour, Habermas 


\section{Selfless and strategic, interpersonal and institutional: A continuum of organizational compassion dimensions}

\section{Introduction}

The turn of the millennium has seen organizational compassion become a topic of increased scholarly and practitioner interest (Worline \& Dutton, 2017). The most widely cited definition of organizational compassion articulates a mutual process of individual and collective NEAR processes: (1) Noticing a colleague's suffering); (2) Empathising with that suffering (through perspective taking) or 'together' (Latin: com) 'suffering' (Latin: passion); (3) Assessing the circumstances of that suffering (sensemaking); and (4) Responding with actions to alleviate employee suffering (Kanov et al. 2004; Dutton, Workman \& Hardin, 2014; Simpson \& FarrWharton, 2017). Historically, both within and outside of the domain of organizational studies, compassion has been discussed in broader terms than those accounted for in this scholarly definition (Simpson, Clegg \& Pitsis, 2014a). It has further been contested on the basis of competing assumptions related to its supposed selfless-selfishness, sentimentality-rationality, care-instrumentality. Although these tensions are present within the organizational compassion literature, they are seldom discussed in a manner that makes them salient. Acknowledging these tensions also gives rise to concerns about whether compassion can at all be practised within the organizational context as a purely virtuous end, or if any organizational compassion would by necessity be an appropriation of the virtue for the instrumental means of enhanced profitability. In this paper, we embrace the challenge of making these tensions salient and grappling with their complexities. We do so by asking professionals representing varied industries and organizational levels what organizational compassion means to them.

Rather than merely revealing hidden underlying tensions, which some scholars have recently suggested are paradoxical (Simpson \& Berti, 2019), and questioning if all organizational compassion is an appropriation of a powerful virtue, we also consider how these tensions can be 
harmonised. We accordingly turn to Habermas's theory of 'communicative action' as an analytical lens. Scholars such as Cooper and Burrell (1988) and Burrell (1994) describe Habermas' (1987) project of synthesising philosophy and empirical social science as invaluable to organizational theorists needing to defend and transcend the dual competing objectives of modern performativity with post-modern emancipation, the latter described managerially as "freeing employees from unnecessarily alienating forms of work organization" (Alvesson \& Willmot, 1992, p. 433). Scherer and Palazzo (2007, p. 1097) similarly describe Habermas' project as an approach "in which both forms of coordination-ethical discourse and economic bargaining - are taken into account". We analyse our findings with insight from an adaptation of Habermas' (1987) theory of 'communicative action', which sees dialogue as the ultimate expression of human potential and as a means of transcending competing tensions (Habermas, 1996).

We structure the paper as follows. We initially review the literature, considering current and past theorising, revealing organizational compassion as a highly contested topic involving competing views: as both an individual virtue as well as a strategic institutional practice, as both irrational and rational, as feminine and masculine, and as having both internal and external targets. We also justify our adaptation and use of Habermas' theory of coordinated communication as our analytical lens and follow up by describing our methodology and analytical frame. In our discussion, we consider possibilities for navigating apparent contradictions in various conceptualisations of organizational compassion through an on-going Habermasian process of dialogue and coordinated action, where apparent contradictions are reframed as potentially complementary, synergistic and energising. Our paper contributes to the organizational compassion literature by providing broader theorising of organizational compassion, problematizing assumed oppositions and suggesting means for integrating and transcending them. 


\section{Competing Conceptualisations of Compassion}

A survey of broader literature, including from philosophy and sociology and organizational studies, reveals many competing conceptualisations of compassion, including as an individual virtue, as a clever strategy, as sentimental emotion and as responsible, rational institutional practices (Simpson, Clegg \& Pitsis, 2014a). Below we consider the various conceptualisations we find most relevant concerning organizational implications.

Compassion is generally conceived as an individual virtue, driven by conscience, deontological moral duty, emotion or sentimentality. Rousseau $(1762,1767)$ saw compassion as the natural human condition before becoming corrupted by societal influences promoting selfish aspirations for domination, control and power. Accordingly, in the traditional organizational context, where it is assumed decisions are based upon rational choice, compassion has traditionally been viewed as irrelevant at best (Thompson, 1975; du Gay 2008). At worst, particularly the for-profit business context wherein profit maximisation is generally the measure of success, compassion is viewed as incompatible and even reprehensible. A manager's decision to act with an ethic of compassion is seen to impose irrational inefficiency on the company, robbing shareholders of dividends due to the added costs associated with providing additional measures of care to address suffering. Noble Prize winning economist Friedman $(1967 ; 1970)$ defended the notion that greed is good (Friedman, 1979), arguing that managers who contributed to social causes were acting outside of their legal remit and engaged in theft. As famously formulated by Adam Smith (1776) (as well as Mandeville [1806] and Voltaire [1778] before him), a narrow focus on selfish self-interest with minimal government interference or distortion of the market is supposed to provide the greatest benefit to the greatest number, due to the paradoxical working of what Smith termed the 'invisible hand' (p. 260). Targeted social action according to this view is inefficient and ineffective in providing actual benefit and should, 
therefore, be left to not-for-profit organizations such as religious institutions, charities, hospitals, schools and NGOs (Friedman, 1967; 1970).

More recently, however, the argument that views compassion as inefficient has been reversed, with strategic compassion being justified on the basis of economic rationality as a contributor to company performance, productivity and profitability (Benioff \& Southwick, 2004; Peters, 1986; Fryer, 2013; Kavan, 2005). It is particularly within the context of post-bureaucratic era (Josserand, Teo \& Clegg, 2006; McKenna, Garcia-Lorenzo \& Bridgman, 2010), where organizations rely on skilled knowledge workers contributing intangible creative, innovative and informational expertise, rather than manual labour in manufacturing work, that organizational compassion has seen a growth in prominence (Peters, 1986; Simpson, Clegg \& Pitsis, 2014a). Compassion is not merely relevant to the context of the knowledge economy, however, Boyle and Healy (2003) see compassion as a facet of spirituality that enables employees to deal with work that is profane, involving a great deal of emotional labour (funerary services, police, medical services and family law).

Compassionate institutional practices of social responsibility and addressing stakeholder needs, which were previously seen as business constraints, apparently contribute more sustainable profitability in the longer term (Benioff \& Southwick, 2004; Benioff \& Adler, 2007; Cameron, Bright \& Caza, 2004; Cameron, Mora, Leutscher \& Calarco, 2011; Kaven, 2005; Mackey, Friedman \& Rodgers, 2005; Van de Velde, Vermeir \& Corten, 2005). When employees view their work as driven by positive and virtuous practices and contributing real value to society, it invokes a greater sense of pride and identification with the organization with employees orienting towards the work not just as a job or career opportunity but as a calling (Mackey \& Sisodia, 2013; Wrzesniewski, McCauley, Rozin \& Schwartz, 1997). The internalisation of social concerns by the organization can engender new creative approaches towards redefining efficiencies in the value chain, reimagining products and markets and 
cultivating cluster development with a sustainable supply chain to facilitate shared value (Porter \& Kramer, 2011). The potential downside of this argument for a strategic application of organizational compassion is that it can be viewed as a benign form of exploitation, domination and control using soft-power, made all the more effective because it works invisibly in a manner that does not seem like power at all (Simpson, Clegg \& Freeder, 2013). Recipients have mixed views towards strategic compassion, some accepting that it is at least a starting point with others arguing that if the motive for compassion is personal gain, then it is not genuine compassion (Simpson, Clegg \& Pitsis, 2014b; Simpson et al. 2014c). A critical determinant here could be whether or not strategic compassion initiatives meet the NEAR criteria and have the effect of alleviating suffering.

Differing perspectives on which party ought to take responsibility for other people's suffering both within the workplace and in broader society poses another challenge concerning the place of institutional practices of compassion. As observed by Tsui (2013), despite Friedman's (1970) argument that organizations cannot be socially responsible because they are not people and only people can be socially responsible, many for-profit enterprises nonetheless engage in compassion. Fleming, Roberts and Garsten (2013, p. 341) describe Friedman's argument accusing managers who contribute company funds towards social causes on compassionate grounds of engaging in theft as leading to "the strange conclusion that a manager is actually irresponsible if he or she becomes concerned". Solomon (2004, p. 1029) is similarly critical arguing that corporations are communities where "mutual respect, caring and compassion are what we all in fact expect and demand in our various jobs and positions" (p. 1040). As Nike discovered, practices such as outsourcing manufacturing to companies in developing countries with minimal workplace health-and-safety regulations and no laws against paying minimal wages to child labourers are not acceptable to many potential customers (Bennet \& Lagos, 2007). Even if the organization is not driven to refrain from such activities on the basis of 
selfless compassion, in many instances, they may be obliged to do so on the grounds of strategic compassion, for the sake of corporate reputation management and avoiding consumer boycotts and other scandals.

Compassion can be viewed as irrational sentiment: arbitrary, emotional, biased and therefore unreliable and inadequate (Nussbaum, 2003), particularly as a basis for organizational action, which is the basis for Thompson's (1975) critiques, written within the context of public administration: 'Administrative compassion can be thought of as special treatment, as "stretching" the rules, as the pre-modern "rule of men" rather than the "rule of law"' (p. 20). In Thompson's view, “The modern organization by its nature, can offer only impersonal, categorised, noncompassionate treatment" (p. 20). Contrasting with these views about the importance of cold rationality, Solomon (1997) and Grant (1988) argue that organizations need more feminine compassion to counter masculine assumptions justifying aggressive business practices of bullying, mass retrenchments and other socially irresponsible practices in the pursuit of an overly rational profit imperative as the sole measure of success. Pullen and Rhodes (2015) similarly lament that compassion, as an embodied, more feminine response to ethical concerns, is undermined by organizations privileging more disembodied, masculine, overly reflexive, rational responses.

Thompson (1975) and du Gay's (2008) views that compassion is necessarily irrational is also contested by research suggesting that organizational compassion can inform and indeed be embedded within rational processes where a culture of compassion is supported by institutional structures such as formal assistance programs for employees in times of need (Lilius, Kanov, Dutton, Worline \& Maitlis, 2011a). Routines promoting awareness of existing community services can also help disseminate information about the importance of paying attention to the suffering of others - increasing the likelihood that it will be recognised and responded to within the organization. Holding regular meetings, creating formal roles and programs and even open 
organizational architecture, have all been suggested as organizational practices that promote enhanced awareness of organizational suffering and increased compassion responding (Lilius, Kanov, Dutton, Worline \& Maitlis, 2011b). Even philosopher Nietzsche (1997), a major compassion critic, suggests with characteristic hyperbole the possibility of a more rational, nonbiased, systematic approach to compassion, one that he sexistly distinguishes as the "more manly brother of compassion" (p. 79). This is a compassion of rational strength expressed at an emotional distance: "If I must be compassionate," Nietzsche says, "I do not want it to be called as such; and if I am, then preferably from a distance" (Nietzsche, 2002, p. 67). Cartwright (1984) argues that distance spares the compassion recipient humiliation of being the object of another's charity. Distance thereby preserves the receiver's dignity, shielding them from developing a low sense of self-esteem and dependency. With distance the giver is also provided anonymity, eliminating the potential weakness of bragging, and minimising sentimental attachments (Pullen \& Simpson, 2009).

As suggested already, organizational compassion also need not be restricted to internal relations between co-workers, as some organizations have an expressed compassionate mission with regards to its products and services (Benioff \& Southwick, 2004) targeted towards those external to the organization, even non-human actors. For example, at an industry level, Lawrence and Phillips (2004) note the role of compassion in the isomorphic transformation of Canada's commercial whaling industry into a "whale-watching industry" (p. 689). This transformation was precipitated by a change in popular social perceptions of the whale as a dangerous beast "to be feared and hunted", to depictions of the whale as a "creature worthy of empathy, compassion and even admiration" (p. 695) with "human qualities such as compassion and bravery" (p. 703). Although Kanov et al. (2004) suggest that an organizational capacity for compassion is more likely to develop in non-governmental organizations (NGOs) (i.e. not-forprofit organizations) with an altruistic pro-social mission to provide important community 
services as opposed to a strategic mission to maximise profits (for-profit organizations), this is not necessarily the case. Studies have found compassionate responses are as likely to occur (or not) both in NGOs as in for-profit organizations (Simpson, Clegg \& Cunha, 2013), suggesting that all organizations are capable of compassion responding (Madden, Duchon, Madden \& Plowman, 2012). Routine organizational practices highlighting a culture of care, therefore, appear more important to compassion responding than organizational mission.

The above analysis indicates that organizational compassion can be conceived more broadly than is generally the case in the organizational literature where compassion tends to be viewed as a virtuous positive interpersonal process (i.e. Cameron, Bright \& Caza 2004). Organizational compassion is more varied, comprising of apparently contradictory aspects: selfless and strategic, interpersonal and institutional, feminine and masculine, sentimental and rational, with internal and external targets. A reason for choosing to narrowly focus on virtuous interpersonal relations might be that some of the additional dimensions appear antithetical, even paradoxical in the way they appear to undermine the virtue of compassion through appropriation, or "colonisation" to use the Habermasian term. Focusing on the most virtuous, desirable or acceptable facets of compassion while ignoring others could be compared to the denial response to a paradox, where one competing pole is selected or separated at the exclusion of the other which is denied (Putnam, Fairhurst \& Banghart, 2016).

\section{Transcending Paradoxical Tensions}

Within the organizational context, paradox has been defined as "contradictory yet interrelated elements that exist simultaneously and persist over time" (Smith \& Lewis 2011, p. 382). Paradoxes are contradictions that appear "logical in isolation but absurd and irrational when appearing simultaneously" (Lewis, 2000, p. 760) leading to the paralysing of action. Tensions are inherent to organizing, often remaining latent and only becoming salient with the emergence of changing circumstances. Some of the organizational compassion dimensions discussed above 
such as selfless, individual, or sentimental appear logical on their own - but become paradoxical when considered alongside their antithetical strategic, institutional or rational counterparts.

The paradox literature acknowledges that the problem with denying one competing paradoxical pole in favour of another, is that it does not actually address the contradictions, which are therefore likely to re-emerge at a later time, and in the meantime cause anxiety, frustration and even operational paralysis (Jarzabkowski, Lê \& Van de Ven, 2013; Hargrave \& Van de Ven, 2016). We suggest with respect to compassion, that the separation and selection of one competing pole of selfless-selfish, or sentimental-rational, highlighting one while denying the other, has led to compassion's outright rejection by a long line of philosophers spanning from Plato (1992) to Spinoza (1996), as well as Kant (1996) and Nietzsche (1966, 1997, 1998, 2002). These philosophers, focusing on compassion's emotional dimensions, viewed compassion as a sentimental passion that undermines self-control, rationality and accordingly, as a poor guide for good conduct. Nietzsche (1966, 1997, 1998, 2002) additionally saw compassion as driven by guilt or manipulative intent both on the part the giver and the receiver, who each seek to generate a sense of obligation in the other. Similarly, as discussed above, within the organizational domain, Thompson (1975) and more recently du Gay (2008) have reasoned that there is no place for compassion in administration due to its inherent irrational unfairness.

Scholars who study organizational paradox argue that a much healthier and beneficial (but also more difficult) response to paradox, in contrast to separation, selection or denial is transcendence, which involves making tensions salient and leveraging their respective forces by placing opposing paradoxical poles "in a novel relationship to each other" (Putnam, Fairhurst \& Banghart, 2016, pp. 128-9). Transcendence, harnesses competing tensions to produce greater power and energy and is achieved as continuous acts of paradoxical cognition (Smith \& Tushman, 2005), rebalancing (Janssens \& Steyaert, 1999; Tracy, 2004), renegotiation (Bednarek, Paroutis \& Sillince, 2017), situational reframing (Westenholz, 1993; Lüscher \& Lewis, 2008) 
and reorganizing material configurations (Abdallah, Denis \& Langley, 2011). In search of a means of accepting and empowering the complexity of a broader conceptualisation of compassionate action within the organizational context, one that makes tensions salient and involves neither selection or separation, least of all outright rejection, we turn to Habermas (1984) for insight.

\section{Habermasian Synthesis}

Habermas' (1987) theory of communicative action provides tools that might facilitate engaging with the complexity and contradictions of differing conceptualisations of organizational compassion. We do not propose an exact correspondence between Habermas' ideas with the dimensions of organizational compassion suggested in our literature review, nor do we even intend to engage with Habermas without adaptation or critique. Rather our proposed project entails engaging with aspects of Habermas' mature theory as a starting point for developing a broader organizational compassion theory. Habermas draws on discourse to address problems of social order, viewing communication as the basis for coordinated social action (Burrell, 1994; Fryer 2012). In the process of coordinated communicative action, social reality is constituted through argumentative exchanges between actors, where discourse forms the basis of mutual understanding. A hearer's acceptance of a speaker's utterance (even tacitly) denotes successful communication, as the consensus that forms the basis for coordinated action. Acceptance of an utterance is not dependent upon its actual correspondence to reality but instead on its acceptability to the hearer (Habermas, 1984).

Implicit discourse rules provide the necessary preconditions for establishing consensus and resolving problematic truth claims (Habermas, 1990). These include rules of logic (requiring logical argument without self-contradiction), rules of reason (good reason must be presented when disputing claims) and governance (discourse must be voluntary and free of coercion). While these pre-conditions may never be fully realised, they must be present to an extent to 
provide a basis for communicative rationality. Habermas sees this communicative rationality enacted at two levels of society comprising of Lifeworld and Systems (Rasche \& Scherer, 2014).

The lifeworld achieves social integration via the communicative understanding of individuals and their shared plans of action (Habermas, 1987). It represents the stock of knowledge assumptions (i.e. moral norms, culture-specific values, ethical, social rules and beliefs, whose meanings are justified and legitimated on the basis of their acceptance by a social group) that people take for granted as they coordinate with others in understanding situations and planning actions. The lifeworld is both constituted and reinforced through interpersonal relations between individuals making sense of their co-inhabited world. Increased complexity in modern society with its individualism, anonymity, mass media and erosion of traditional values has introduced added complexity in social integration, revealing the limitations of the lifeworld as a mechanism for social coordination.

Systems are the mechanisms increasingly relied upon in modern society to coordinate activities based on instrumental rationality geared towards choosing the most efficient means for a given end. Although Habermas (1987) agrees that systemic specialisation (e.g. of the economy, politics, law, science and religion) is integral to social action in modern society, he also points to the risks associated with this type of coordination. Systems do not coordinate based on mutual agreement about validity claims (i.e. communicative rationality), but rather through their own system-specific logics (e.g. profit, power, justice, truth, belief). As there is not enough agreement about values to allow the system to wield power, lifeworld and systems become decoupled. Systems can only provide integration and coordination within their own boundaries and fail to support broader social integration. Decoupling leads to a situation wherein system integration prevails over the broader integrative effects of the lifeworld with the system eventually colonising (controlling) the lifeworld. As "systems depend on the normative foundations provided by the lifeworld" (Elder-Vass, 2018, p. 231), colonisation (control) by system creates a 
variety of social pathologies, including the single-sided rationalisation of the private sphere on the basis of utilitarian imperatives and the disempowering of the public domain through overly bureaucratic decision-making processes.

Habermas has drawn criticism for his view of lifeworld and system as discrete categories of action and coordination that operate as two different social spheres (see for example Fraser 1989; McCarthy 1991; or Mouzelis 1997). Critics observe to the contrary that communicative agreements are seen within the public space (of systems), while technologies of profit and power are found within the private domain such as the private family home (lifeworld). Elder-Vass (2018, p. 233) draws on a version of Habermas (1987) to redefine the ontology of lifeworld and system arguing that "the concepts of lifeworld and system can be rescued by reframing them, not as domains of action, but as classes of causal mechanism". Accordingly, in this paper, we classify lifeworld as denoting mechanisms arising from humanistic and virtuous communicative interaction, while we classify system as denoting mechanisms of power (profit, efficiency and control). Furthermore, as hinted by Broadbent and Laughlin (2009), we additionally take a realist view of the lifeworld and system mechanisms as operating on a continuum, with their "pure" forms existing only as abstract archetypical constructions. We, therefore, do not see colonisation as the result of decoupling as much as it is the result of moving too much towards system, diminishing the influence of lifeworld to the extent that it is no longer felt.

Applying this adaptation of Habermas' theory to the context of organizational compassion, we anticipate will facilitate making salient underlying tensions, including those related to the appropriation or colonisation of organizational compassion by managerial interests. We further propose that Habermas' theory of communicative action might also provide insight on how these apparent contradictions can be harmonised and transcended, to minimise the harm of exploitation and generate maximum synergy and benefit. 


\section{Methodology}

\section{Data collection}

We sought the views of industry practitioners on the significance of organizational compassion through semi-structured exploratory interviews. Our respondents were 32 professionals representing a range of Portuguese organizations and institutional sectors. Interviewees were selected deliberately using theoretical sampling (Eisenhardt \& Graebner, 2007), considering the number of participants and information saturation (Miles \& Huberman, 1994; Yin, 2009).

Interviewees ages ranged between 36 and 66 years, the majority $(\mathrm{N}=23)$ holding higher educational degrees with the remainder having undertaken year 12 equivalent studies with training in specialised professional or technical courses. All interviewees currently work, with the majority $(\mathrm{N}=22)$ having worked in executive leadership positions or management teams/departments. The most represented sector in our sample was the $2^{\text {nd }}$ sector of private companies $(\mathrm{N}=21)$, followed by the $1^{\text {st }}$ sector of public companies $(\mathrm{N}=19)$, with the $3^{\text {rd }}$ sector of non-governmental organizations $(\mathrm{N}=8)$ the least represented. Interviews were conducted individually with all 32 respondents using the same interview script. The essential question asked of all respondents was: 'Is there such thing as organizational compassion and if so, how is it defined'. Each interview lasted an average of 30 minutes.

\section{Data analysis}

As is common in inductive research the qualitative analysis started interactively with comparisons between the data and the literature (Corbin \& Strauss, 2008; Strauss \& Corbin, 1998). This involved collection, ordering and analysis of data, comparing the findings with the literature to identify and classify similarities and differences (Eisenhardt, 1989; Eisenhardt \& Graebner, 2007). We conducted the first level of coding by analysing the data line by line to identify and code core themes. This analysis generated a more general and abstract level of 
conceptual categories in four theoretical compassion dimensions: selfless, strategic, interpersonal and institutional (each with further sub-categories).

Higher order categorisation involved further categorising two of our four dimensions as representing Habermas' internal values and ethics-driven lifeworld (interpersonal and selfless) and the other two as representing Habermas' performative rationality driven systems (institutional and strategic compassion). Habermas describes how the lifeworld and system become "decoupled" through a lack of communication. We extended this language to describe each compassion dimension as a partner in a couple: by pairing one lifeworld dimension with a corresponding systems dimension, two couples were derived: the first labelled selfless compassion and strategic compassion, with the second, interpersonal compassion and institutional compassion (Figure 1). The emergent conceptualisation reveals organizational compassion as complex, involving internal lifeworld values of virtuous altruistic intentions as well as more rational systems informed motives and practices. Departing from Habermas, however, we recognise that no compassion relation is purely selfless or strategic; or purely interpersonal or institutional, rather we view each partner as signifying an extreme lifeworld/system archetype, with actual practices falling on a continuum between the extremes represented in each couple. Accordingly, there is no sense of "decoupling" in our conceptualisation. Instead colonisation is the outcome of systems instrumentality overwhelming lifeworld to the extent that lifeworld loses its influence as the foundation of organizational compassion relations.

\section{Insert Figure 1}

\section{Findings}




\section{Selfless compassion and strategic compassion}

Selfless compassion. In the selfless-strategic compassion couple, selfless compassion was viewed as springing from internal ethical virtues or conscience. The discourses in this category highlighted the importance of empathy and sacrifice for those in a situation of vulnerability or suffering in the workplace context. Compassion was viewed as something that is expressed for an employee or colleague for no other reason than human kindness, as described by one of our respondents: 'That is not easy, it is a really genuine thing. One that is born within us ... it is real'. Interviewees in this group spoke of compassion as an authentic selfless expression of human conscience directed as empathic support towards others who suffer: 'to feel compassion, to be hand in glove, to have a soul and total surrender'.

Perspective taking and the ability to identify with and empathise with another's pain as potentially one's own was also highlighted: 'The compassion I have for the other is related to the ability to put myself in the other person's shoes'. Another interviewee expressed that it is natural to feel human concern, empathy and genuine interest in the struggles experienced by others not only at work but also in their private lives, and not only for co-workers but also for clients:

It is what leads us to show concern, empathy for others because of their conditions, inside the organization and at the personal level and later. Organizational compassion must be something identifiable by others in practice, inside and outside the organization, and this interest in the other. I see it not only for the organization's employees but also for its users/clients.

Other relevant micro-discourses associated with selfless compassion were linked to a commitment to ethics of human rights, workplace health-and-safety, work-life balance and corporate-social-responsibility:

I believe it is important to have compassion at work, it has to do with the human being, with people. Compassion is expressed in the employees' rights and it has to do with the person it is a more humanist vision, also needed in temporary work, in crisis situations, and in the employee's 
mobility in which human rights are becoming less and less present- Here, compassion is a balance.

Some interviewees associated organizational compassion with social justice: 'professional compassion must always be integrated into the values, standards, social justice... within this, compassion makes sense'. Overall, we see selfless compassion as related to values, ethics, conscience and social justice that drive compassionate responding towards those who suffer. It is debatable exactly how selfless or selfish compassion motivation might be (as discussed above, philosophers have indeed debated this over the millennia); accordingly, we view our data as suggesting a continuum with selflessness and strategic compassion representing theoretical extremes.

Strategic compassion. In the selfless-strategic couple, strategic compassion describes the value of organizational compassion as a contributor to enhanced organizational performance, productivity and profitability. This perspective sees maintaining values of humanism and compassion as contributing towards employee satisfaction, a necessary precondition for organizational performance and competitiveness: 'To be more productive, the more compassion and passion there is the better the people adapt and evolve, it is necessary to create work conditions where people are happy'. In a similar vein a respondent with vast organizational experience suggested that compassion is relevant to all sectors, including for-profit organizations: 'The aim of organizations from the $2^{\text {nd }}$ and $3^{\text {rd }}$ sectors is to make profit, they must achieve objectives but the organization is only as good as its people, if the latter are not satisfied, the former does not work.'

Compassion, according to some of our respondents, need not necessarily involve directly responding to manifest suffering but is instead about preventing suffering and creating the workplace conditions that contribute to employee satisfaction. Important initiatives here include assuring employees have work-life balance, comfortable workplace conditions as well as work 
recognition and rewards. On the importance of work-life balance, one respondent from the education sector expressed: 'Compassion is balance ... concerned with the values of equality, laws and with the spaces that each employee needs, with schedules' flexibility, to conciliate family and work, to work at home.' Another interviewee highlighted the importance of compassion as employee benefits and rewards, which contribute to employee satisfaction, motivation and performance:

Compassionate actions can be generated through diversified events, values, training, education or character development and other initiatives. These aspects improve the environment, which affects productivity in the company. It is important to make life easier within companies compassion for the employees' personal lives. Initiatives that multinationals could promote within the companies' own marketing actions would be, for example, the award of a tourist trip to their employees.

Strategic organizational compassion was also described as important for managing organizational reputation by addressing concerns over fair work practices and corporate social responsibility - which we discuss further under the heading of institutional compassion. Overall, strategic compassion is concerned with providing support to employees to ensure greater performance and productivity. Here compassion is expressed not necessarily as responding to manifest suffering but as providing the conditions that don't just ease suffering but make work activity comfortable and even inspiring. These actions are mostly enacted institutionally through systems and routines. By encouraging employees to deal with each other compassionately, however, strategic compassion can also be fostered at the interpersonal level.

\section{Interpersonal compassion and institutional compassion}

Interpersonal compassion. Our second couple represents two levels of enacting organizational compassion as interpersonal compassion and institutional compassion. Interpersonal compassion concerns personal discretionary efforts of addressing others' suffering within the organizational 
context, including supporting others with institutionally related problems or tasks and maintaining a supportive psychological context for work performance. One interviewee, a graphic artist, described a compassion episode from his own workplace, which he explained as driving by his valuing another as human: 'What I did was value that person when other people were devaluating her'. This humanistic view of compassion is similar to the Kantian imperative to treat others: 'never merely as a means to an end, but always at the same time as an end' (Kant, [1785] 1993: 33). In the words of another respondent organizational compassion also involves seeking: 'To know how to look at people. I am thinking about empathy as a whole, to make them important people for the organization, to know their opinions, ideas, look at them as the human beings they are.'

Relevant supportive factors here include relational proximity, similarity, closeness, and minimal power distance that enable people to identify with one another, express on-going care and respond in times of distress (Dutton, Workman \& Hardin, 2014). An interviewee involved in the military, with vast experience in team leadership, described organizational compassion as related to relationships, availability, support, understanding, respect and equality:

In fact, it is the relational component and of the person highlighted ... it is to be available for people and., be considerate of people ... it is to be available to provide support and to understand the other ... To respect the other as equal.

An example of organizational compassion provided by an interviewee in the health sector involved reaching out to help other colleagues in trying times such as being made redundant at work: 'Compassion can be more important where there is a dismissal, crisis. It is easier if people receive help in this process with a series of situations of solidarity and human resources can help look for another job.'

Overall, interpersonal compassion depends on close personal connections facilitating identification with 'the other' who suffers, acknowledging that their suffering could be one's own. 
When an organization formalises processes to facilitate care for others who suffer, it not only relieves the distress of the sufferer but also reassures other organizational members about their own safety and wellbeing. We refer to the systematisation of compassionate formal organizational policies, routines and procedures as institutionalised compassion, discussed next.

Institutional compassion. Interpersonal practices of compassion contrast with the concept of institutional compassion encapsulated in the interviewee's beliefs that compassion can be organised and embedded within organizational structures, systems and culture. Some respondents explained the relationship between interpersonal and institutional compassionate practices as linked through compassionate organizational culture:

Compassion must be part of the organization culture: at the level of communication with the other, relationships, and of taking care of us to take care of the other'. Similarly, another interviewee saw the 'attitude of a compassionate person' is a starting point from which 'the culture of the organization must follow.

These concepts were further advanced with a view that compassion must be reinforced and communicated throughout the organization systemically as formal policies, routines and processes: 'support, solidarity, understanding and mutual help must translate into a system that works'. A way of systemising compassion at the organizational level, according to another respondent, was by facilitating greater proximity through reducing power distances that impede identification and empathy towards other members: 'It must be genuine, [it must be] concern and empathy in practice, cutting hierarchies'. The importance of minimising hierarchies to facilitate compassion was expressed by another interviewee, working in the education sector, as follows: 'With hierarchies, I believe it is difficult to feel these compassion actions, I feel that more among peers, (teacher(s)-teacher(s); teacher (s)-student(s).'

Other relevant micro-discourses associated with institutional compassion concerned organizational commitment to policies supporting humanistic values (discussed earlier under 
selfless compassion) where the institutional imperative of profit maximisation is tempered by rules and procedures supporting a commitment to corporate-social-responsibility, workplace health-and-safety, work-life balance and human-rights. As stated by one interviewee, 'professional compassion must always be integrated into values, standards, social justice ... within this, compassion makes sense.' One interviewee made the association between organizational compassion and human rights by denying the relationship, highlighting the ambivalence associated with this topic:

In the work context, compassion does not exist. What must be present is the respect of the collaborators' rights and duties when they have problems (...). There is a set of strategic rules that makes the collaborator feel well in his/her organization (...), for example, the possibility to have the afternoon free to give support to a child.

Organizational compassion was also linked to the social responsibilities organizations have towards the needs of stakeholders within the communities in which they operate, an idea associated with organizational reputation management: 'We develop support activities in the community... We hand in gifts to people who are in a vulnerable situation of disease and in retirement homes...'

The enactment of organizational compassion at the institutional level through compassionate culture and systems was also connected to the notion of human centred leadership. In the words of an interviewee in the human resources department of a $2^{\text {nd }}$ sector organization: 'Human resources must be oriented towards people. We boost compassion within this structure and based on leadership.' Compassionate leadership, as described by an interviewee in the telecommunications sector, is benign, benevolent and paternalistic: 'Leaders must get close to people ... know them, create camaraderie ... display attitudes of affection and firm attitudes, as parents do.' Another respondent spoke of the importance of leading by example, with firmness and compassion, 'it is the leader who must build the house and get people on the right task, value 
and correct mistakes... it is compassion... motivate, value and empower...' The leader's compassion was also linked to discretionary behaviours of recognising and rewarding exceptional performance: 'Compassion actions are not part of the employment contract. Regarding payments where there was an excess of revenues, he always gave a small prize to the employees, i.e. an individual compensation to each employee'. Another respondent described using the authority of their leadership position to modify general procedures to help an employee undergoing hardship:

As a company leader, I used to help my subordinates in their hardest personal life/family moments. An example of these attitudes was to put forth a part of the salary when something happened. I remember an employee who had a fire at his home and I paid forth his/her salary in advance.

Overall institutional compassion concerns the systematisation of interpersonal compassion relations through the development of a compassionate culture, the espousal of humanistic values, practices of corporate social responsibility and citizenship, as well as people-centred leadership.

\section{Discussion}

The findings indicate that organizational compassion has various dimensions: selfless and strategic, interpersonal and institutional. Some of the ideas, particularly about strategic compassion, further suggest potential appropriation or colonisation of compassion in the interests of managerial and corporate advantage. In the following section, we explore the implications of these findings when viewed through our adapted Habermasian lens. Our analysis further highlights how each of these competing tensions can be harmonised through coordinated communication.

\section{Colonisation of the lifeworld by system}


In identifying selfless and interpersonal compassion with lifeworld, and strategic and institutional compassion with system, application of Habermas' (1987) theory suggests colonisation as a concern, as system can only provide integration and coordination within its own rationalities that fail to support broader integration. As system depends on lifeworld for its own apparent legitimacy and validity, however, colonisation by system undermines the very notion of the lifeworld: "although the system is embedded in and depends on the lifeworld, the former tends to encroach upon, to displace and even destroy, the latter" (Finlayson, 2005, p. 56). System thereby generates a self-defeating logical contradiction involving single-sided rationalisation on the basis of utilitarian instrumental logics. When latent tensions are thus made salient as a paradox, it can lead to the paralysis of action.

Within the context of our organizational compassion dimensions, the colonisation of selfless compassion by strategic compassion would undermine the very notion of organizational compassion as surrendered self-sacrifice to benefit another colleague in a suffering condition. Similarly, with the colonisation of interpersonal compassion by institutional compassion, individuals within the organization would cease to be compassionate to one another, or others outside the organization. Expectations that only the institution has a responsibility to provide support to those who suffer thereby undermines the very notion of a compassionate organization. The contradiction generated, sees the replacement of selfless and interpersonal compassion with strategic and institutional systems that have as their ultimate objective, not care, but instrumental logics of enhanced organizational performance, productivity and profitability. In our study, even if our data were interpreted as not showing sufficient support for selfless and interpersonal compassion being grounded by strategic and institutional compassion, based on Habermas' theory, we believe it should. At stake is the perceived legitimacy of the systems' compassion initiative: if the system dimensions are successful in colonising the lifeworld dimensions, the 
colonisers lose their social legitimacy as authentic expressions of concern for the suffering of others and organizational compassion appears as a charade (Simpson, Clegg \& Pitsis, 2014).

Application of our adapted Habermasian theory, however, suggests that colonisation is complete only when systems instrumentality overwhelms lifeworld, eclipsing lifeworld considerations as a driver of organizational compassion relations. Along the continuum between complete colonisation and "pure" lifeworld driven compassion, there are many shades. Furthermore, from an organizational perspective, systems can, in fact, expand compassion relations beyond lifeworld capabilities. Accordingly, there is less reason to be suspicious of strategic compassion per se; rather it is system's overwhelming and diminishing the influence of lifeworld that is problematic. Taking this view provides theory for suggesting how apparently incompatible tensions could be harmonised and transcended through coordinated action. If the tensions of organizational compassion can be made to endure, not through oscillation between one or the other pole using strategies of denial, forced integration or separation (Poole \& Putnam 2008), but as harmonised tensions, then the lifeworld/systems couple is also constituted as an example of paradox transcendence (Putnam, Fairhurst \& Banghart, 2016). The important consideration here for organizational compassion as transcended paradox is that it leverages and magnifies the power of compassion beyond its lifeworld contexts. Such transcendence through linking and leveraging enduring interdependent tensions, it has been suggested, is at the heart of leadership excellence (Lewis, Andriopulos \& Smith, 2014; da Cunha, Clegg \& Cunha, 2002).

This analysis of the potential colonisation of the lifeworlds of selfless and interpersonal organizational compassion by the systems of strategic and institutional compassion provides powerful insight into why compassion has historically been responded to with rejection (Plato, 1992; Spinoza, 1996) or denial (Nietzsche (1966, 1997, 1998, 2002). Engagement with Habermas' theorising not only provides keys for analysing this problem but also suggests the means for its alleviation through a transcendent solution. Viewing organizational compassion as 
involving various dimensions with competing poles representing Habermas' lifeworld and system, offers tools for harnessing and transcending these tensions to generate powerful synergies.

\section{Communicative action as a response to colonisation}

Communicative action is the solution Habermas (1987) optimistically offers for problems of colonisation and the subsequent logical contradictions that undermine the very processes the coloniser seeks to obtain for instrumental objectives. Communicative action is a mutual deliberative process of open dialogue between two or more concerned parties, with each deliberately adjusting and coordinating activities to account for and accommodate the others' needs. It comprises of reflexive dialogue wherein participants to an argument are open to learning from one another, including by questioning the assumptions of knowledge learned through cultural upbringing, which go unquestioned.

Communicative action contrasts with strategic action. The language of strategic communication is only concerned with defending the views and interests of the speaker as a means of persuasion and manipulation. Such instrumentality fails to account for the integrating effects of communication within society. It thus leads back to an individual perspective (selfish, self-interest) of rationality as a means-end goal-oriented calculation, underpinned typically by economic imperatives. Consequently, the necessary communicative process underlying in modern societies is obscured. According to the theory of communicative action, reason and ethics are gathered from the legitimate form accepted by the social group interacting according to agreed understandings of justice and truth. Yet, strategic action, due to its efficiency, becomes so widespread that it makes its way into the lifeworld, decreasing its potential to ensure communicative rationality and legitimate ethical organizational activities. 
In communicative action, the orientation towards achieving success transforms into an orientation for achieving mutual understanding and consensus that transcends and leverages differences. In this deliberative process, lifeworld oriented social discourse and systems oriented economic bargaining are both given consideration as relevant modes of coordination (Habermas, 1996, 1998). The aim is not for a Utopian and revolutionary alternative to capitalistic enterprise, but to circumscribe the neo-liberal normalisation of pure economic rationality in all domains, with compassionate social-democratic considerations and procedures (Scherer \& Palazzo, 2007).

\section{Integration of compassion dimensions through communicative action}

Rather than readily concluding that all organizational compassion represents an example of colonisation by managerial interests, the findings of this study can be interpreted as revealing that organizational compassion works as a social coordination mechanism within general forms of selfless/interpersonal and strategic/institutional relations. Application of Habermas' (1987) notion of communicative action would seek to integrate and transcend contradictions to discover harmony between these different mechanisms of organizational compassion. The approach would involve bringing together stakeholders representing various aspects of organizational compassion (selfless/strategic, interpersonal/institutional) into respectful, open dialogue, where the different parties learn to deliberately adjust and coordinate their actions to account for and accommodate the others' needs. Such dialogue would reveal that the benefits of strategic compassion are limited without a foundation of selfless compassion that is rooted in notions of human virtue, conscience or ethics. Without such an authentic and sincere foundation, strategic compassion is more or less (depending on where it is placed on the continuum) a façade, and is often perceived and experienced as such, with limited motivational effects on stakeholders (Simpson, Clegg \& Cunha, 2013). Similarly, as suggested by some participants in this study, institutional compassion must extend from the compassionate behaviours of individual members. 
The strength of institutional compassion is limited if it is not founded on compassionate interpersonal dealings between individuals.

The overall objective of applying communicative action within organizational compassion would be circumscribing strategic/institutional normalisation of organizational compassion, with selfless individual considerations, replacing conflict and contradiction with harmony and integrity. Selfless/interpersonal compassion can be individualised and personal, yet also unstable and unreliable: it is after all discretionary action. Strategic/Institutional compassion can be stable and impartial, yet it can also be instrumental and impersonal. Coordinating both together through communicative action can achieve a synergy that offers the benefits of both whiles also addressing the tensions of these various organizational compassion dimensions (Simpson \& Berti, 2019). Promoting dialogue between organizational members representing these different dimensions will ensure that organizational compassion is expressed not just rhetorically but also practically.

\section{Conclusion}

We sought to broaden the treatment of organizational compassion within scholarly research by asking 32 professionals from various organizational sectors about the existence and definition of organizational compassion. Analysis of the responses identified various conflicting dimensions to organizational compassion that we categorised as (1) selfless sacrifices of kindness, (2) strategic actions to motivate employees and manage reputation, (3) interpersonal relations of care in response to suffering and as (4) systemic institutional procedures ensuring workplace safety and corporate social responsibility. Some of these dimensions are implicit in existing definitions and theorising of organizational compassion; however, our analysis makes them explicit. Others are absent from current definitions. Specifically, our findings and emergent model bring attention to the dimension of strategic compassion, which can be awkward for those seeking to promote organizational compassion as sincere fellow feeling for others who suffer. Also 
discussed is the sub-dimension of general social values directed towards those outside of the organization as a concern for corporate social responsibility and stakeholder considerations. These social concerns, which our participants identified as aspects of organizational compassion, are also generally absent from theorising on organizational compassion narrowly defined as responding to the pain and suffering of individuals within the organization.

With insight from Habermas' (1987) notions of lifeworld and system, we paired our four theoretical organizational compassion dimensions as two couple mechanisms, which we theorised as operating on a continuum: selfless compassion (lifeworld) and strategic compassion (system), as well as interpersonal compassion (lifeworld) and institutional compassion (system). A powerful insight that emerged from this analysis was that the two foundations of organizational compassion are lifeworld mechanisms of selfless compassion and interpersonal compassion. These foundational, internal, mostly emotional drivers of organizational compassion are systemised as rational processes of strategic and institutional compassion, extending compassion beyond the lifeworld. Habermasian' analysis suggests that there is always a real threat that system might colonise processes of selfless and interpersonal compassion, wherein system eclipses lifeworld's influence and compassion is justified merely by rational economic arguments. Such an approach relegates the importance of ethics and virtue to financial imperatives. As a response, we advocated the application of Habermas' approach of communicative action, wherein organizational stakeholders engage in open dialogue to understand the needs of various representative groups and deliberately adjusting actions to coordinate behaviours in a manner that meets the requirements of all concerned parties.

Our reinterpreting lifeworld and system as mechanisms operating on a continuum rather than as separate domains suggests, however, that they may not be entirely as incompatible as Habermas believes. Applied to the compassion context we see how system can, in fact, magnify the power of lifeworld concerns. This analysis problematises the supposed opposition between 
emotional and rational, individual and organizational, ethical and strategic forms of compassion - suggesting that the paradoxical tensions of lifeworld and system can be leveraged and transcended to produce greater power and energy (Putnam, Fairhurst \& Banghart, 2016).

All research has its limitations. A limitation of this study is that despite efforts to achieve a representational balance amongst interviewees, the majority of the participants were male and only eight professionals had experience in the not-for-profit sector. Additionally, all of the respondents were from Portugal, representing a relatively homogeneous cultural group that might offer responses less relevant to other cultural contexts (Hofstede, Hofstede \& Minkov, 1991). Notwithstanding these limitations, the findings of this study constitute a significant contribution and justify future research projects to achieve more significant conclusions.

Many avenues exist for further research in exploring the facets of compassion generated in this study. One course could be to empirically examine the facilitators and inhibitors of coordinated meaning within each of the proposed couples (selfless-strategic, interpersonalinstitutional) identified in this study. It might also be that there are other paradoxical dimensions that could be explored, which were not highlighted in our findings but are suggested in the literature including: femininity and masculinity (Pullen \& Rhodes, 2015; Pullen \& Simpson 2009), low and high power distance (Dutton, Frost, Worline, Lilius, \& Kanov, 2002), as well as internal and external organizational contexts. The development of an assessment tool to analyse and provide feedback to organizations on their compassion profile based on their practices within each dimension would also constitute an important contribution. Another area for research would be to identify if there is an approximate ideal ratio for synergistically leveraging the contradictions between the dimensions representing lifeworld and those representing system. Research with some 200-hospital patients exposed to high levels of stress found that those with optimum levels of functioning demonstrated a 3:1 ratio, expressing three positive emotions for every negative emotion (Shrira et al., 2011). Similarly, in the happiness literature the balance 
between the stress induced by a challenging task and confidence in ones skill level to meet the challenge is understood to produce an enjoyable flow state of being in the zone, where complete absorption in the moment while performing a task causes time to just fly (Csikszentmihalyi, 1990). A question particularly relevant to the current study would be, what is the approximate ideal ratio for benefiting from the instrumentality of system without actually colonising lifeworld by overwhelming and eclipsing its influence? At what system/lifeworld ratio do compassion practices appear to lose authenticity and instead be seen as a façade?

In terms of practical application of communicative action dialogue, future research could explore the potential of Rosenberg's (1999, 2003, 2005a,b) approach of Compassionate Communication (otherwise known as Non-Violent Communication) as a practical means for applying the implications of this study, using the model to identify the different relevant groups to engage in dialogue facilitated through the processes of Compassionate Communication. The method of Compassionate Communication is concerned with the mutual expression of three communication components: (1) self-empathy derived from compassionate introspection into one's own internal emotional state, (2) empathic understanding and connection with other people's emotional experiences, and (3) authentic self-expression of one's own observations, feelings, needs or requests, in a manner that likely inspires other people's compassion. Compassionate Communication has been applied across a range of settings including organizations (Lasley, 2005), parenting, education, mediation, psychotherapy, prisons, and peacebuilding programs in conflict zones within Africa, the Balkans and the Middle East (Havva, 2009; Danielsen, 2013). With such a program already well established with a promising track record, research could study whether encouraging the Compassionate Communication within organizations might be a practical means for applying the Habermasian implications of the findings from this study encouraging open dialogue between different groups representing the organizational compassion counterparts of Habermas' lifeworld and systems. Our results 
suggest organizational compassion is real, powerful and multifaceted. It has the potential to be emotional, sentimental, selfless, virtuous, discretionary and interpersonal as well as strategic, rational, instrumental, calculated and institutional. All of these facets are important, yet as recognised by philosophers through the ages, they also have associated areas of concern creating tensions that can be detrimental at the interpersonal and institutional levels. A key thesis of this paper is that through communicative action organizations can transcend compassion paradoxes by leveraging systems to expand the power of compassion beyond lifeworld contexts. While in this relationship of integrated lifeworld/systems transcendence there is the ever-present threat of colonisation of the lifeworld by system, communicative action presents as a framework for limiting this concern and cultivating the best of compassion within the organizational context. 


\section{REFERENCES}

Abdallah, C., Denis, J. L., \& Langley, A. (2011). Having your cake and eating it too: Discourses of transcendence and their role in organizational change dynamics. Journal of Organizational Change Management, 24(3), 333-348.

Alvesson, M., \& Willmott, H. (1992). On the idea of emancipation in management and organization studies. Academy of Management Review, 17(3), 432-464.

Bednarek, R., Paroutis, S. \& Sillince, J. (2017). Transcendence through rhetorical practices: Responding to paradox in the science sector. Organization Studies (01708406), 38(1), 77-101.

Bennett, W.L. \& Lagos, T. (2007). Logo logic: The ups and downs of branded political communication. The Annals of the American Academy of Political and Social Science, 611(1), 193-206.

Benioff, M. \& Southwick, K. (2004). Compassionate capitalism. Prompton Plains, NJ: Career Press.

Benioff, M. \& Adler, C. (2007). The business of changing the world: Twenty great leaders on strategic corporate philanthropy. New York: McGraw Hill Professional.

Boyle, M. V. \& Healy, J. (2003). Balancing mysterium and ónus: Doing spiritual work within emotion laden organizations. Organization, 10(2), 351-373.

Broadbent, J., \& Laughlin, R. (2009). Performance management systems: A conceptual model. Management Accounting Research, 20(4), 283-295.

Burrell, G. (1994). Modernism, post modernism and organizational analysis 4: The contribution of Jürgen Habermas. Organization Studies, 9(2), 221-225.

Cameron, K.S., Mora, C., Leutscher, T. \& Calarco, M. (2011). Effects of positive practices on organizational effectiveness. The Journal of Applied Behavioural Science, 47(3), 266-308.

Cameron, K.S., Bright, D. \& Caza, A. (2004). Exploring the relationships between organizational virtuousness and performance. American Behavioural Scientist, 47(6), 766-90. 
Cartwright, D.E. (1984). Kant, Schopenhauer, and Nietzsche on the morality of pity. Journal of the History of Ideas, 45(1), 83-98.

Cooper, R. \& Burrell, G. (1988). Modernism, Postmodernism and Organizational Analysis: An Introduction. Organization Studies, 9(1), 91-112.

Corbin, J. \& Strauss, A. (2008). Basics of qualitative research: Techniques and procedures for developing grounded theory (3rd Ed.). Thousand Oaks, CA: Sage.

da Cunha, J. V., Clegg, S.R. \& Cunha, M. P. (2002). "Management, paradox, and permanent dialectics.” In S. R. Clegg (Ed.). Management and Organization Paradoxes: 11-40.

Csikszentmihalyi, M. (1990). Flow. New York, NY: Harper \& Row.

Danielsen, G. (2013). Meeting human needs, preventing violence: Applying human needs theory to the conflict in Sri Lanka (Master's Thesis, University del Salvador, Buenos Aires).

du Gay, P. (2008). Without affection or enthusiasm: Problems of involvement and attachment in 'responsive' public management. Organization, 15(3), 335-353.

Dutton, J. E., Frost, P., Worline, M. C., Lilius, J. M., \& Kanov, J. M. (2002). Leading in times of trauma. Harvard Business Review, 80(1), 54-61.

Dutton, J.E., Worline, M.C., Frost, P.J., \& Lilius, J. (2006). Explaining compassion organizing, Administrative Science Quarterly, 51, 59-96.

Dutton, J.E., Workman, K..M., \& Hardin, A,E. (2014). Compassion at work. The Annual Review of Organization Psychology and Organizational Behaviour, 1, 277-304.

Eisenhardt, K. M. (1989). Building theories from case study research. Academy of Management Review, 14, 532-550.

Eisenhardt, K, M. \& Graebner, M, E. (2007). Theory building from cases: Opportunities and challenges. Academy of Management Journal, 50, 25-32.

Elder-Vass, D. (2018). Lifeworld and systems in the digital economy. European Journal of Social Theory, 21(2), 227-244. 
Fraser N (1989) Unruly Practices: Power, Discourse and Gender in Contemporary Social Theory. Cambridge: Polity.

Finlayson J. G. (2005). Habermas: A very short introduction. Oxford: Oxford University Press.

Fleming, P., Roberts, J., \& Garsten, C. (2013). In search of corporate social responsibility: Introduction to special issue. Organization, 20 (3), 337-348.

Friedman, M. (1967). Capitalism and freedom. Chicago: University of Chicago press.

Friedman, M. (1970). The social responsibility of Business is to increase its profits. The New York Times Magazine,13. Retrieved from http://www.colorado.edu/ studentgroups/libertarians/issues/frie...

Friedman, M. (1979). Interview with Phil Donahue. Retrieved from https://www.youtube.com/watch?v=RWsx1X8PV_A

Fryer, B. (2013). The rise of compassionate management (finally), Harvard Business Review, Boston. Retrieved from http://blogs.hbr.org/2013/09/the-rise-of-compassionate-management-finally/>.

Fryer, M. (2012). Facilitative leadership: drawing on Jürgen Habermas' model of ideal speech to propose a less impositional way to lead. Organization, 19(1), 25-43.

Grant, J. (1988). Women as managers: What they can offer to organizations. Organizational Dynamics, 16(3), 56-63.

Habermas, J. (1984). The Theory of Communicative Action (Vol. 1). Boston, MA: Beacon Press.

Habermas, J. (1987). The Theory of Communicative Action (Vol. 2). (T. McCarthy, Trans.). Boston, MA: Beacon Press.

Habermas, J. (1990). Moral consciousness and communicative action. Cambridge: MIT Press

Habermas, J. (1996). Between facts and norms: Contributions to a discourse theory of law and democracy. Cambridge, MA: MIT Press. 
Hargrave, T.J. \& Van de Ven, A.H. (2016). Integrating dialectical and paradox perspectives on managing contradictions in organizations, Organization Studies, p. 0170840616640843.

Havva K, (2009). Nonviolent Communication in Political Conflicts, USAK. Yearbook of International Politics and Law, 2, 349-362.

Hofstede, G., Hofstede, G. J., \& Minkov, M. (1991). Cultures and organizations: Software of the mind: McGraw-Hill London.

Janssens, M. \& Steyaert, C. (1999). The world in two and a third way out? The concept of duality in organization theory and practice, Scandinavian Journal of Management. 15(2), 121-39.

Jarzabkowski, P., Lê, J.K. \& Van de Ven, A.H. (2013). Responding to competing strategic demands: How organizing, belonging, and performing paradoxes coevolve, Strategic Organization, 11(3), $245-80$.

Josserand, E., Teo, S. \& Clegg, S.R. (2006). From bureaucratic to post-bureaucratic: the difficulties of transition, Journal of Organizational Change Management, 19 (1), 54-64.

Kanov, J. M., Maitlis, S., Worline, M. C., Dutton, J. E., Frost, P., \& Lilius, J. M. (2004). Compassion in organizational life. American Behavioural Scientist, 47, 808-827.

Kant, I. ([1785] 1993). Grounding for the metaphysics of morals (J. W. Ellington, Trans. 3rd ed.). Indianapolis: Hackett.

Kant, I. (1996). The metaphysics of morals. Cambridge: Cambridge University Press.

Kavan, H. (2005). Compassionate capitalism: How corporations can make doing good an integral part of doing well, Women In Management Review, 20 (3), 208-10.

Lasley, M. (2005). Difficult Conversations: Authentic Communication Leads to Greater Understanding and Teamwork. Group Facilitation: A Research and Applications Journal, 7, 1320. Lazarus, R.S. (1991). Emotion and adaptation, Oxford University Press, New York.

Lawrence, T. B., \& Phillips, N. (2004). From Moby Dick to Free Willy: Macro-cultural discourse and institutional entrepreneurship in emerging institutional fields. Organization, 11(5), 689-711. 
Lewis, M. W., Andriopoulos, C., \& Smith, W. K. (2014). Paradoxical leadership to enable strategic agility. California Management Review, 56(3), 58-77.

Lewis, M.W. (2000). Exploring paradox: Toward a more comprehensive guide, Academy of Management Review, 25(4), 760-76.

Lilius, J. M., Worline, M. C., Maitlis, S., Kanov, J. M., Dutton, J. E., \& Frost, P. J. (2008). The contours and consequences of compassion at work. Journal of Organizational Behaviour, 29, 193-218.

Lilius, J. M., Kanov, J. M., Dutton, J. E., Worline, M. C. \& Maitlis, S. (2011a). Compassion revealed: What we know about compassion at work (and where we need to know more). In K. S. Cameron \& G. Spreitzer (Eds.), The handbook of positive organizational scholarship (pp. 273287). Oxford: Oxford University Press.

Lilius, J. M., Kanov, J. M., Dutton, J. E.,Worline, M. C \& Maitlis, S. (2011b). Understanding compassion capability. Human Relations, 64, 873-899.

Lüscher, L.S. \& Lewis, M.W. (2008). Organizational change and managerial sensemaking: working through paradox, Academy of Management Journal, 51(2), 221-40.

Mackey, J., Friedman, T.J. \& Rodgers, T. J. (2005). Rethinking the social responsibility of business. Journal of Reason, 10, 15-7.

Mackey, J. \& Sisodia, R.S. (2013), Conscious capitalism: Liberating the heroic spirit of business. Boston: Harvard Business Press.

Madden, L., Duchon, D., Madden, T. \& Plowman, D.A. (2012). Emergent organizational capacity for compassion. Academy of Management Review, 37, 689-708.

Mandeville, B. (1806). The Fable of the bees; Or, private vices, public benefits. London: T. Ostell.

McKenna, S., Garcia-Lorenzo, L. \& Bridgman, T. (2010). Managing, managerial control and managerial identity in the post-bureaucratic world. Journal of Management Development, 29(2), 128-36. 
McCarthy T (1991) Complexity and democracy: or the seducements of systems theory. In: Honneth A and Joas H (eds) Communicative Action: Essays on Jürgen Habermas's The Theory of Communicative Action. Cambridge: Polity, pp. 119-39.

Miles, M., \& Huberman, A. (1994). Qualitative Data Analysis ( ${ }^{\text {nd }}$ ed). Thousand Oasks: Sage. Mouzelis NP (1997) Social and system integration: Lockwood, Habermas, Giddens. Sociology 31(1): $111-19$.

Nietzsche, F. (1966). Beyond good and evil (W. Kaufmann, Trans.). In W. Kaufmann (Ed.), Basic writings of Nietzsche (pp. 181-435). New York: The Modern Library.

Nietzsche, F. (1997). Daybreak (R.J. Hollingdale, Trans.). Cambridge: Cambridge University Press.

Nietzsche, F. (1998). On the genealogy of morals (D. Smith, Trans.). New York: Oxford University Press.

Nietzsche, F. (2002). Thus spoke Zarathustra (A. Del Caro, Trans.). Cambridge: Cambridge University Press.

Nussbaum, M.C. (2003). Upheavals of thought: The intelligence of emotions. Cambridge Cambridge University Press.

Peters, T. (1986). Competition and compassion. California Management Review, 28 (4), 11-26.

Plato. (1992). Republic (G.M.A. Grube \& C.D.C. Reeve, Trans.). Indianapolis: Hackett Publishing, Co., Inc.

Poole M.S., Putnam L. L. (2008).Organizational Paradox. In Clegg S. R., Bailey J. R. (Eds.), International Encyclopedia of Organizational Studies (pp. 1146-1149, Vol. 3). Thousand Oaks, CA: Sage.

Porter, M.E. \& Kramer, M.R. (2011). Creating shared value. Harvard Business Review, 89 (1/2), $62-$ 77.

Pullen, A. \& Simpson, R. (2009). Managing difference in feminized work: Men, otherness and social practice. Human Relations, 62 (4), 561. 
Pullen, A. \& Rhodes, C. (2015). Ethics and embodiment in organizations. Organization. 22(2), 159165.

Putnam, L. L., Fairhurst, G. T., \& Banghart, S. (2016). Contradictions, Dialectics, and Paradoxes in Organizations: A Constitutive Approach. The Academy of Management Annals, 10 (1), 65-171.

Rasche, A., \& Scherer, A.G. (2014). Jurgen Habermas and Organization Studies: Contributions and future prospects. In: P. Adler., P. du Gay., G. Morgan \& M. Reed (Eds.), Oxford Handbook of Sociology, Social Theory, and Organization Studies (pp.158-181). Oxford: Oxford University Press.

Rosenberg, M. (1999). Nonviolent communication: A language of compassion: PuddleDancer Press Del Mar, CA.

Rosenberg, M. (2003). Nonviolent Communication: A Language of life ( ${ }^{\text {nd }}$ ed.). Encinitas, CA: PuddleDancer Press.

Rosenberg, M. (2005a). The Heart of Social Change: How to Make a Difference in Your World. Encinitas, CA: PuddleDancer Press.

Rosenberg, M. (2005b). Speak Peace in a World of Conflict: What You Say Next Will Change Your World. Encinitas, CA: PuddleDancer Press.

Rousseau, J.J. (1762/2003), Emile (W.H. Payne, Trans.). Amherst, NY: Prometheus Books

Rousseau, J.J. (1767). The social contract or principles of political right (G. D .Cole, Trans.).LondonScherer, A. G., \& Palazzo, G. (2007). Toward a political conception of corporate responsibility: Business and society seen from a Habermasian perspective. Academy of Management Review, 32(4), 1096-1120.

Scherer, A. G., \& Palazzo, G. (2007). Toward a political conception of corporate responsibility: Business and society seen from a Habermasian perspective. Academy of Management Review, 32(4), 1096-1120. 
Shrira, A., Palgi, Y., Wolf, J. J., Haber, Y., Goldray, O., Shacham-Shmueli, E., \& Ben-Ezra, M. (2011). The positivity ratio and functioning under stress. Stress and Health, 27(4), 265-271.

Simpson, A.V. \& Berti, M. (2019). Transcending organizational compassion paradoxes by enacting wise compassion courageously. Journal of Management Inquiry. (accepted for publication).

Simpson, A.V., Clegg, S. \& Cunha, M.P. (2013). Expressing compassion in the face of crisis: Organizational practices in the aftermath of the Brisbane floods of 2011. Journal of Contingencies and Crisis Management, 21(2), 115-24.

Simpson, A.V., Clegg, S. \& Freeder, D. (2013). Power, compassion and organization. Journal of Political Power, 6 (3), 385-404.

Simpson, A.V., Clegg, S. \& Pitsis, T. (2014a). I used to care but things have changed: A genealogy of compassion in organizational theory. Journal of Management Inquiry, 23(4), 347-59.

Simpson, A., Clegg, S., \& Pitsis, T. (2014b). Normal compassion: A Framework for compassion decision making, Journal Business Ethics, 119 (4), 473-491.

Simpson, A. V., Clegg, S., Lopez, M. P., Cunha, M. P., Rego, A., \& Pitsis, T. (2014c). Doing compassion or doing discipline? Power relations and the Magdalene Laundries. Journal of Political Power, 7(2), 253-274.

Simpson, A. V., \& Farr-Wharton, B. (2017). NEAR Organizational Compassion Scale: validity, reliability and correlations. Paper presented at the Australian and New Zealand Academy of Management (ANZAM), RMIT, Melbourne Australia.

Smith, A. (1776). An inquiry into the nature and causes of the wealth of nations. London: Cass.

Smith, W. K., \& Lewis, M. W. (2011). Toward a theory of paradox: A dynamic equilibrium model of organizing. Academy of Management Review, 36(2), 381-403.

Smith, W. K., \& Tushman, M. L. (2005). Managing strategic contradictions: A top management model for managing innovation streams. Organization Science, 522-536.

Solomon, R. C. (2004). Aristotle, ethics and business organizations. Organization, 25(6), 1021-1043. 
Solomon, R. C. (1997). Competition, care, and compassion: Toward a nonchauvinist view of the corporation. In A. Larson \& R. E. Freeman (Eds.), Women's Studies and Business Ethics: Toward a New Conversation (pp. 144-173). New York: Oxford University Press.

Spinoza, B. (1996). Ethics (E. Curley, Trans.). In E. Curley (Ed.). London: Penguin Books.

Strauss, A, L. \& Corbin, J. (1998). Basics of Qualitative Research: Techniques and Procedures for Developing Grounded Theory ( $2^{\text {nd }}$ ed). Thousand Oaks, CA: Sage.

Tracy, S.J. (2004). Dialectic, contradiction, or double bind? Analyzing and theorizing employee reactions to organizational tension. Journal of Applied Communication Research. 32(2), 119-46.

Thompson, V.A. (1975). Without sympathy or enthusiasm: The problem of administrative compassion. Alabama: University of Alabama Press.

Tsui, A. S. (2013). On compassionate scholarship: Why should we care? Academy of Management Review, 38(2), 167-181.

Van de Velde, E., Vermeir, W. \& Corten, F. (2005). Corporate social responsibility and financial performance. Corporate Governance, 5(3), 129-38.

Voltaire. (1778). Letters concerning the English nation. London: J and R Tonson, D Midwinter, M Cooper and J Hodges.

Westenholz, A. (1993). Paradoxical thinking and change in the frames of reference, Organization Studies. 14(1), 37-58.

Worline, M., \& Dutton, J. E. (2017). Awakening compassion at work: The quiet power that elevates people and organizations: Berrett-Koehler Publishers.

Wrzesniewski, A., McCauley, C., Rozin, P. \& Schwartz, B. (1997). Jobs, careers, and callings: People's relations to their work. Journal of Research in Personality, 31 (1), 21-33.

Yin, R.K. (2009). Case Study Research: Designs and Methods, Applied Social Research Methods Series ( $4^{\text {th }}$ ed.). Thousand Oaks, CA: Sage. 
Figure 1: Data analysis structure

\section{Micro Discourses}

\begin{tabular}{|l|}
\hline Virtues \& Ethics \\
Sacrifice \\
Kindness \\
Perspective taking \\
Authenticity \\
Workplace safety \\
Work-life balance \\
CSR \\
Social justice \\
\hline
\end{tabular}

Performance

Productivity

Employee satisfaction

Employee motivation

Work-life balance

Employee benefits

Reputation management

Efforts to address

suffering

Support with institutional concerns

Supportive psychological environment

Personal connections

Compassionate Culture Systems \& Policies

Flattened hierarchies

Humanistic values (CSR, work-life balance, OHS, human rights, stakeholder concerns)

Human centred

leadership

\section{Higher Order Compassion Category
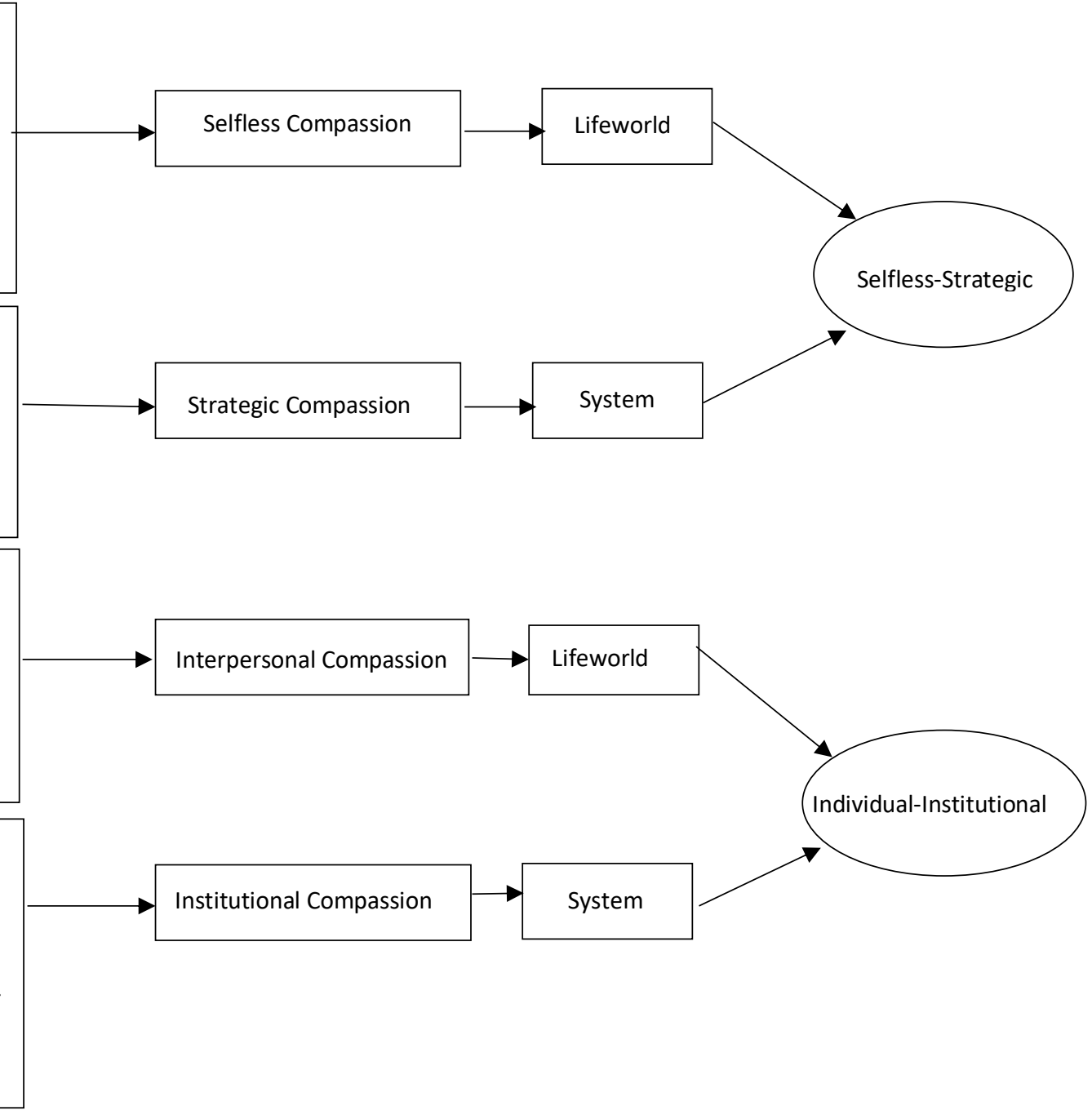


\section{Author biographies:}

Leonor Araújo is a Psychologist and has been working in education and social justice. She is a $\mathrm{PhD}$ student in Social Sciences specializing in Organizational Behavior at the Instituto Superior de Ciências Sociais e Politicas, Universidade de Lisboa, Portugal, and researcher at Centro de Administração e Políticas Públicas - CAPP, Universidade de Lisboa, Portugal. Her research interests relate to Organizational Compassion and Human Capital Development. Her work has been published in journals such as Análise Psicológica and Psicologia, Educação e Cultura.

Ace Volkmann Simpson is Senior Lecturer in Organizational Behavior in the UTS Business School, University of Technology Sydney. His research brings a critical-social perspective to organizational practices, including positive practices of compassion, love and humility. Ace's research has been published in journals such as the Journal of Management, Journal of Business Ethics, Journal of Management Inquiry and Management Learning.

Helena Águeda Marujo is an Assistant Professor at the Instituto Superior de Ciências Sociais e Politicas, Universidade de Lisboa, Portugal, and Integrated Researcher at the Centro de Administração e Políticas Públicas - CAPP, Universidade de Lisboa, Portugal. Helena's research interests relate to Virtuous Organizations, Positive Communities, Corporate Peace and Relational Goods. Helena has edited and collaborated in several books on the topic (Springer, E. Elgar, Worldshare Books by TAOS) and published in Journals such as the Journal of Psychology in Africa and Applied Research in Quality of Life.

Miguel Pereira Lopes is an Associate Professor at the Instituto Superior de Ciências Sociais e Politicas, Universidade de Lisboa, Portugal, and Integrated Researcher at the, Centro de Administração e Politicas Publicas - CAPP, Universidade de Lisboa, Portugal. His research interests relate to Positive and Negative Organizational Studies. His work has been published in journals such as Organization, Journal of Career Development, Journal of Positive Psychology and Journal of Management. 